\title{
A Meta-Analysis of The Effects of Grazing On Plant Diversity, Biomass and Soil Properties of Alpine Grassland On The Tibetan Plateau
}

\section{Wenlong Li}

Lanzhou University

Chenli Liu ( $\sim$ liuchl18@lzu.edu.cn )

Lanzhou University https://orcid.org/0000-0001-6389-8792

Huakun Zhou

Northwest Institute of Plateau Biology

Wenying Wang

Qinghai Normal University

Jing Xu

Lanzhou University

Pengfei Xue

Lanzhou University

Hepiao Yan

Lanzhou University

\section{Research Article}

Keywords: Grazing management, Alpine grassland, Species richness, Biomass, Meta-Analysis, Tibetan Plateau

Posted Date: April 15th, 2021

DOI: https://doi.org/10.21203/rs.3.rs-413371/v1

License: (a) (1) This work is licensed under a Creative Commons Attribution 4.0 International License. Read Full License 
4 Authors: Wenlong Li, Chenli Liu*, Huakun Zhou, Wenying Wang, Jing Xu, Pengfei Xue, Hepiao Yan

5 Names: Wenglong Li, Chenli Liu, Pengfei Xue, Hepiao Yan

6 Institution: State Key Laboratory of Grassland Agro-Ecosystems, College of Pastoral Agriculture

7 Science and Technology, Lanzhou University, Lanzhou 730020, China

8 Names: Huakun Zhou

9 Institution: Key Laboratory of Cold Regions Restoration Ecology, Qinghai Province, Northwest

Names: Wenying Wang

Institution: Department of Life Sciences, Qinghai Normal University, Xining 810008, China

Names: Jing Xu

Institution: School of Agriculture and Forestry Economic and Management, Lanzhou University of

Finance and Economics, Lanzhou 730020, China

First author: Wenglong Li

E-mail: wllee@1zu.edu.cn

Corresponding author: Chenli Liu

E-mail: liuchl18@1zu.edu.cn 


\section{Abstract:}

$\operatorname{Aim}$ As one of the main human disturbance factors in the alpine grassland on the Tibetan Plateau, grazing not only directly affects grassland plant diversity and biomass, but also indirectly changes soil carbon (C) and nitrogen $(\mathrm{N})$ of grassland. Despite of extensive field grazing experiments, the impacts of grazing on grassland diversity, soil $\mathrm{C}$ and $\mathrm{N}$ remain uncertain due to different grazing management.

Methods We conducted a meta-analysis of 70 peer-reviewed publications to evaluate the general response of 11 variables related to alpine grassland plant-soil ecosystems to grazing.

Results The results showed that grazing significantly increased species richness, Shannon-Wiener index and Pielou evenness index by $9.8 \%, 7.3 \%$ and 3.7\%, respectively. Aboveground biomass, belowground biomass, soil organic carbon, soil total nitrogen, soil C: $\mathrm{N}$ ratio and soil moisture decreased by $41.9 \%$, $17.7 \%, 13.1 \%, 12.6 \%, 3.3 \%$ and $20.8 \%$, respectively. Soil bulk density and soil $\mathrm{pH}$ increased by $17.5 \%$ and $2.2 \%$, respectively. Specifically, moderate grazing, long-duration ( $>5$ years) and winter grazing contributed to the increase in the species richness, Shannon-Wiener index, and Pielou evenness index. Aboveground biomass, belowground biomass, soil organic carbon, soil total nitrogen and soil C: $\mathrm{N}$ ratio showed a decreasing trend with enhanced grazing intensity. Furthermore, grazing duration, grazing season, livestock type and grassland type also affected alpine grassland plant diversity, biomass, soil C and $\mathrm{N}$.

Conclusions Grazing is beneficial to the maintenance of plant diversity, but negatively affects the storage of soil $\mathrm{C}$ and $\mathrm{N}$ in alpine grassland on the Tibetan Plateau. We suggest that grazing should follow intermediate grazing practice and synthesize other appropriate grazing patterns, such as seasonal and rotation grazing, thus, further research on grazing management is needed in this regard. 
Key Words: Grazing management; Alpine grassland; Species richness; Biomass; Meta-Analysis; Tibetan Plateau

\section{Introduction}

As an important component of terrestrial ecosystems, grassland accounts for nearly $20 \%$ of the global land surface (Scurlock and Hall 1998). Grassland ecosystem not only supports living and grazing conditions, but also plays a key role in biodiversity conservation, carbon sequestration, sand fixation and climate regulation (Ren et al. 2016; Zhang et al. 2015). There is 3.93 million $\mathrm{km}^{2}$ grassland in China, which accounts for more than $40 \%$ of the total land area. It is mainly distributed in the northern temperate regions and on the Tibetan Plateau (Wang et al. 2019). However, because of human overuse and climate change, grassland has degraded seriously in recent decades, which results in the loss of biodiversity and the degradation of ecosystem functions, such as soil nutrients deficiency and community structure uniformity (Li et al. 2017). Meanwhile, grazing is regarded as one of the most important factors affecting grassland, especially overgrazing, which can lead to grassland degradation. In order to mitigate further deterioration and degradation of grassland, the Chinese government has implemented the relevant ecological restoration programs, such as the Returning Grazing Land of Grassland (Xiong et al. 2016;

Zhang et al. 2015). The main purpose of these programs is to reverse the negative effects of overgrazing and rebuild the ecological functions of degraded grasslands. Although some mitigation strategies have been adopted to reduce the impact of overgrazing, it is necessary to further study the effect of different grazing management on grassland vegetation and soil property.

The Tibetan Plateau is well-known as the "Roof of the World" for its highest elevation in the world and as the "Water Tower" of Asia (Li et al. 2013). As one of the main pastoral areas in China, the Tibetan Plateau is abundant in grassland resources with alpine meadow, alpine steppe and alpine desert grassland, 
which occupies $47.05 \%, 30.98 \%$ and $7.41 \%$ of the total plateau area, respectively (Li et al. 2018a; Tian et al. 2014). Currently, several studies have reported that grazing changes plant diversity, biomass, soil carbon $(\mathrm{C})$ and nitrogen $(\mathrm{N})$ in alpine grassland, but the results of these studies are sometimes controversial. For example, the results of Wu et al. (2014b) showed that grazing decreased species diversity, while Xiong et al. (2014) found that grazing for six years enhanced the species diversity of alpine grassland compared to non-grazing. Zou et al. (2016a) also concluded that the plant diversity in grazing alpine grassland increased significantly compared to fences. Furthermore, previous studies have found that grazing reduced grassland biomass (Lin et al. 2011; Zhao et al. 2016), while a few studies showed that grazing increased biomass (Niu et al. 2009). Different studies also have a marked difference in the effects of grazing on soil property in alpine grassland. Some studies had shown that grazing had negative effects on soil C and N (Li et al. 2016a; Shi et al. 2013; Sun et al. 2011), while others studies found that grazing had no significant effect on soil $\mathrm{C}$ and $\mathrm{N}$ ( $\mathrm{Lu}$ et al. 2015b). In addition, many previous studies have demonstrated that heavy grazing reduced plant diversity, biomass and soil organic carbon (SOC) content in alpine grassland (Dlamini et al. 2016; Sun et al. 2011; Sun et al. 2018), and moderate grazing might help balance species diversity protection and biomass production (Li et al. 2011). However, despite of these effects, the magnitude of grazing effects on alpine grassland varies due to the difference in grazing regime, grazing intensity, grazing duration, grassland types and environmental factors (He et al. 2020; Li et al. 2017).

The meta-analysis provides a robust, quantitative, scientific and comprehensive statistical approach to individual studies (Gurevitch et al. 2018; Hedges et al. 1999). Several studies synthesized the effects of grazing on grassland ecosystems at global and national scales. For example, Zhou et al. (2017a) and Byrnes et al. (2018) conducted a global meta-analysis and indicated that grazing significantly decreased 
belowground $\mathrm{C}$ and $\mathrm{N}$ in grassland ecosystems. Herrero-Jauregui and Oesterheld (2018) reported that species richness significantly decreased as grazing intensity increased on a global scale. Yan et al. (2013) found that, compared to the global average value, grazing had a greater negative effect on grassland total biomass in China. The recent meta-analyses of Yan et al. (2020) and Liu et al. (2021)showed that heavy grazing significantly decreased the biomass and soil total N. However, a synthesis of the effect of grazing on alpine grassland on the Tibetan Plateau is still lacking, which indicated that the general response of alpine grassland on the Tibetan Plateau to grazing remains unclear. Given these studies, it is necessary to integrate the available data to analyze how grazing affects alpine grassland.

In this study, we will apply meta-analysis to synthesize published data to evaluate the impact of grazing on alpine grassland on the Tibetan Plateau. Specifically, our main objectives are to (a) evaluate the magnitude and direction of grazing disturbance on plant diversity, biomass, soil $\mathrm{C}$ and $\mathrm{N}$ in alpine grassland; (b) examine how the different grazing intensity, grazing duration, grazing season livestock type, and grassland type regulate these response variables; and (c) investigate the relationships between these response variables and climate factors under grazing.

\section{Materials and methods}

Data compilation

We searched peer-reviewed papers published before January 2020 using the ISI Web of Science (http://apps.webofknowledge.com) and China National Knowledge Infrastructure (http://www.cnki.net).

The following keywords and combinations were used for retrieval: 'grazing' OR 'fencing' AND 'alpine grassland' OR ‘alpine meadow' OR ‘alpine steppe’ OR ‘soil carbon' OR ‘soil nitrogen’ OR ‘diversity’ OR 'biomass' AND 'Tibet' OR 'Tibetan Plateau' OR 'Qinghai-Tibetan Plateau'. To avoid bias in publication selection, the papers were chosen based on the following criteria: (1) All study results were 
107

from field experiments and must be carried out in the alpine grassland of on the Tibetan Plateau; (2)

There was at least one group of grazing treatment and control group (non-grazing); (3) The experiment must contain at least one pair of target variables; (4) Grazing and control experiments need to be carried out under similar environmental conditions, including orientation, aspect and slope position; (5) Gazing intensity, duration, season and livestock type need to have clear description; (6) All experimental data collection was at the peak of the growing season; (7) The mean, standard deviation (SD) or standard error (SE) and sample size of each variable in the treatment and control group were clearly reported in the paper. Based on these criteria, 70 published papers were selected for this study (Table S1 and Fig. 1).

\section{[Here insert Fig. 1]}

The compiled database included three categories of response variables: (1) Plant diversity. Because different indices represent different aspects of species diversity, we used common indicators of species richness (SR), Shannon-Wiener index $(\mathrm{H})$ and Pielou evenness index (E); (2) Biomass, including aboveground biomass (AGB) and belowground biomass (BGB); (3) Soil. As more than 80\% of grassland biomass and soil nutrients concentrate on the surface soil of $0-30 \mathrm{~cm}$ (Yu et al. 2019). Thus, we only selected the soil depth data at 0-30 cm, mainly including soil organic carbon (SOC), soil total nitrogen (TN), soil C: N ratio, soil bulk density (BD), soil moisture (SM) and soil $\mathrm{pH}$. For each selected literature, we recorded the journal name, study site, longitude, latitude, elevation, mean annual temperature (MAT) and mean annual precipitation (MAP). In cases that the MAT and MAP were not reported in the paper, the data were extracted from the global climate database (http://www.worldclim.org) by using longitude and latitude information (Zhou et al. 2017a).

To detail the impact of grazing on grassland, referring to the research of Zhou et al. (2006) and Sun et al. (2017), the grazing intensity wass determined by the stocking rates (Cao et al. 2011). However, due 
129

130

131

132

133

134

135

to the different stocking capacities in different areas of alpine grassland on the Tibetan Plateau. According to previous studies of He et al. (2020) and Liu et al. (2021), the grazing levels were based on original papers data collection and were divided into light, moderate, heavy and free grazing. Moreover, we also discussed the grazing experiment under different grazing duration (short-term grazing ( $\leq 2$ years), medium-term grazing (2-5 years) and long-term grazing ( $>5$ years)) (Hao and He 2019; Xiong et al. 2016), grazing seasons (winter season grazing, summer season and annual grazing), livestock types (yak, Tibetan sheep, mixed yak and Tibetan sheep) and grassland types (meadow, steppe and desert steppe). Climate factors included MAT ranging from -4 to $7.25^{\circ} \mathrm{C}$ and MAP ranging from 93 to $750 \mathrm{~mm}$. Grazing experimental duration ranges from 0.5 to 20 years. All the raw data were extracted from the texts, tables, and graphics. If data were presented graphically, we used the GetData Graph Digitizer to extract data (ver 2.26, Russian Federation, http://www.getdata-graph-digitizer.com).

\section{Meta-analysis}

The data were analyzed by adopting a meta-analysis method based on Hedges et al. (1999) and Luo et al. (2006). A natural logarithm of the calculated response ratio $(R R)$ was used as the effective amount to indicate the effect of grazing on the grassland related variables. The $R R$ was calculated by Eq (1).

$$
R R=\ln \left(\overline{X_{t}} / \overline{X_{c}}\right)=\ln \left(\overline{X_{t}}\right)-\ln \left(\overline{X_{c}}\right)
$$

where $\overline{X_{t}}$ and $\overline{X_{c}}$ are the mean value in the grazing treatment and the control group (nongrazing), respectively. The variance (v) of $R R$ was estimated by Eq (2).

$$
v=\frac{S_{t}^{2}}{n_{t} \bar{X}_{t}^{2}}+\frac{S_{c}^{2}}{n_{c} \bar{X}_{c}^{2}}
$$

where $n_{t}$ and $n_{c}$ represent the sample size of the grazing treatment and the control (non-grazing), respectively. $S_{t}$ and $S_{c}$ are the standard deviation of the concerned variable in the grazing treatment and control group, respectively. In order to obtain smaller variability and higher accuracy, the weighted 
151

152

153

response ratio $\left(R R_{++}\right)$was used to improve the statistical accuracy, and the weight factor $(w)$ of effect value $(R R)$ of each study was the inverse of the variance $(w=l / v)$. The means of response ratio $\left(R R_{++}\right)$ was calculated from each pair of control and grazing treatment of individual $R R$ (Zhou et al. 2017a). The formula for calculating the weighted response ratio is shown in $\mathrm{Eq}$ (3).

$$
R_{++}=\frac{\sum_{i=1}^{m} \sum_{j=1}^{k} w_{i j} R R_{i j}}{\sum_{i=1}^{m} \sum_{j=1}^{k} w_{i j}}
$$

where $w_{i j}$ is the weight factor for each group. The $m$ and $k$ are the number of datasets and data points in the category group, respectively. The effect of grazing was considered significant if the $95 \%$ confidence interval (CIs) value of $R R_{++}$for a variable did not overlap zero with CIs given in Eq (4)

$$
95 \% C I=R R_{++} \pm 1.96 S\left(R R_{++}\right)
$$

The overall standard error $(S)$ was calculated using the following formula by Eq (5).

$$
S\left(R R_{++}\right)=\sqrt{\frac{1}{\sum_{i=1}^{m} \sum_{j=1}^{k} w_{i j}}}
$$

We applied the random-effects models to calculate the mean effect size for each study, which used bootstrapping method to obtain the lowest and highest values to derive the bootstrap $95 \%$ confidence intervals (95\% CIs) based on 5000 iterations (Janssens et al. 2010; Zhou et al. 2018). When the 95\% CIs of $R R_{++}$did not overlap with zero, it indicated that grazing had a significant impact on selected variables. On the contrary, the amount of effect overlapping with zero indicated that there was no obvious difference under various grazing conditions. The percentage change of the variable was calculated with the following formula by $\mathrm{Eq}(6)$.

$$
\text { Percentage }(\%)=\left(e^{R R_{++}}-1\right) \times 100 \%
$$

To further examine the effects of categorical classes, the total heterogeneity $\left(Q_{T}\right)$ was composed of within-group heterogeneity $\left(Q_{W}\right)$ and between-group heterogeneity $\left(Q_{B}\right)$ (Ren et al. 2018). To clarify 
172

173

whether there was a distinct difference among different treatments within the same group. If the probability value of $Q_{B}$ was lower than 0.05 , the response rates were significantly different among various subgroups (Li et al. 2016b). We used Rosenthal's fail-safe to check for publication bias (Table S1) (Rosenberg 2005). If the fail-safe number is more than $5 n+10$ ( $n$ is the number of observations used in the analysis), then the result is considered as a reliable estimate of the true effect (Ren et al. 2016; Zheng et al. 2019). All meta-analysis were calculated by METAWIN 2.1 software (Hedges et al. 1999; Rosenberg et al. 2000) and the plots were made on SIGMAPLOT software (SIGMAPLOT 11.0 for Windows; Systat Software lnc., San Jose, CA, USA). Furthermore, we performed linear regression analysis to explore the relationships between the response ratio $(R R)$ of variables and MAT and MAP under grazing.

\section{Results}

Effects on grassland plant diversity

Overall, our meta-analysis showed that grazing significantly increased all the grassland diversity indices, including species richness $(+9.8 \%)$, Shannon-Wiener index $(+7.3 \%)$ and Pielou evenness index (+3.7\%) (Fig. 2). Moderate and free grazing significantly increased species richness by $18.8 \%$ and $13.1 \%$, respectively, but light and heavy grazing had no effect on species richness (Fig. 2a). The ShannonWiener index and Pielou evenness index significantly increased except for heavy grazing (Fig. 2b and 2c). For the experimental duration, short and medium grazing duration did not significantly increase species compared to non-grazing, but long duration grazing increased species richness by $13.8 \%$. In contrast, short-duration grazing significantly reduced Shannon-Wiener index (-13.0\%) and Pielou evenness index (-9.2\%). In terms of the grazing season, winter grazing contributed to increasing species richness $(+34.8 \%)$, Shannon-Wiener index $(+26.6 \%)$ and Pielou evenness index $(+6.3 \%)$. With respect 
194

195

to livestock type, Tibetan sheep grazing significantly increased Shannon-Wiener index $(+10.2 \%)$ and Pielou evenness index $(+8.1 \%)$, but did not change species richness. For grassland type, grazing significantly increased Shannon-Wiener index $(+18.4 \%)$, Pielou evenness index $(+11.7 \%)$ of alpine steppe, and species richness (+11.0\%) of alpine meadow (Fig. 2).

\section{[Here insert Fig. 2]}

Effects on grassland biomass

On average, the results showed that grazing significantly decreased AGB (-41.9\%) and BGB (17.7\%) (Fig. 3). With respect to different grazing intensity, all grazing intensities had significant negative effects on AGB as the intensity of grazing increased, but only heavy and free grazing decreased BGB. When the short duration grazing had the greatest impact on AGB (-58.2\%), BGB did not change. Moreover, medium and long duration grazing had significant negative effects on AGB and BGB. For different grazing seasons, winter grazing had less impact on AGB than summer and annual grazing, while it had no significant effect on BGB. Different livestock type grazing showed different magnitudes of changes for biomass, and mixed grazing had the greatest reduction in AGB compared with yak and Tibetan sheep grazing. Furthermore, grazing had significantly reduced AGB and BGB in different alpine grassland (Fig. 3).

\section{[Here insert Fig. 3]}

Effects on grassland soil $\mathrm{C}, \mathrm{N}$, and related variables

Overall, grazing significantly decreased SOC (-13.1\%), TN (-12.6\%), C: N ratio (-3.3\%) and SM ($20.8 \%)$, but enhanced $\mathrm{BD}(+17.5 \%)$ and soil $\mathrm{pH}(+2.2 \%)$ (Fig. 4). Specifically, with the increase of grazing intensity, grazing had a negative impact on $\mathrm{SOC}, \mathrm{TN}, \mathrm{C}: \mathrm{N}$ ratio and $\mathrm{SM}$, while it had a positive effect on $\mathrm{BD}$ and $\mathrm{pH}$. Regarding grazing duration, long duration grazing had the greatest impact on SOC 
increased soil $\mathrm{BD}$ and $\mathrm{pH}$, while it was decreased $\mathrm{SM}$. With reference to grazing season, all grazing season significantly reduced SOC, TN and SM, but enhanced soil BD. When grouped by livestock type, mixed grazing had the greatest impact on SOC, TN and C: $\mathrm{N}$ ratio. Tibetan sheep grazing had the most significant impact on soil BD, SM and $\mathrm{pH}$. Additionally, based on the limited number of observations $(<20)$, grazing had no significant effect on soil C, N and SM in steppe and desert steppe grassland. However, the opposite result was discovered for meadow grassland (Fig. 4).

\section{[Here insert Fig. 4]}

Relationship between response variables and climate factors under grazing

We used linear regression to investigate the relationship between the response ratio $(R R)$ and climate.

Specifically, our analysis showed that there was no significant correlation between the response ratio of plant diversity (e.g., SR, H, and E) and MAT and MAP (Table 1). No significant relationships were observed between the response ratio of biomass, $\mathrm{SOC}$ and $\mathrm{TN}$ and climate. Moreover, the response ratio of soil $\mathrm{C}$ : $\mathrm{N}$ ratio, $\mathrm{SM}$ and soil $\mathrm{pH}$ were significantly negatively correlated with $\mathrm{MAT}(p<0.05)$, but it was not significantly correlated with MAP. The response ratio of BD declined with the increase of MAP $(p<0.05)$, but it was not significantly correlated with MAT.

\section{[Here insert Table 1]}

Taken together, the results illustrated the effect of grazing on plant diversity, biomass and soil C, N and their possible mechanisms in alpine grassland (Fig. 5). In short, grazing directly reduced grassland productivity and SM, enhanced soil BD, and affected soil chemical properties. Moreover, grassland vegetation and soil properties were mutually influential (Fig. 5).

\section{[Here insert Fig. 5]}




\section{Discussion}

Response of grassland plant diversity to grazing

Our meta-analysis suggests that grazing had significantly increased species richness, ShannonWiener index and Pielou evenness index in alpine grassland on the Tibetan Plateau (Fig. 5). These results were in line with a recent meta-analysis by Lu et al. (2017), which indicated that grazing could increase the spatial heterogeneity, enhance the niche of grassland communities, promote the coexistence of species and improve plant species diversity in alpine grassland. With regard to grazing intensity, we found that moderate and free grazing remarkably increased species richness, but the effect was no significant in the light and heavy grazing. This finding was in accordance with the previous study of alpine grassland (Ganjurjav et al. 2015). It is probably because light grazing inhibited the growth of dominant vegetation to a certain extent and enhanced the competitiveness of inferior species. In addition, Joubert et al. (2017) also found that moderate grazing increased the species richness in Afromontane grassland. Light, moderate and free grazing significantly increased Shannon-Wiener index and Pielou evenness index except for heavy grazing. The changing community structure of alpine grassland by grazing led to the reduction of grassland biomass, so that some palatable plants gradually disappeared, such as grasses and legumes plants. Thus, the dominant species were reduced, which ultimately affected plant ShannonWiener index and Pielou evenness index (Li et al. 2013; Zhou et al. 2006).

Notably, long-term ( $>5$ years) grazing increased species diversity compared to non-grazing, but the effects of short and medium duration grazing on species diversity were not significant, which might be associated with the following reasons. Firstly, with the succession of vegetation, plant communities changed due to long-term non-grazing, which led to the predomination of dominant species. Secondly, some less competitive species gradually decreased or disappeared from plant communities because of 
competition, light resource or nutrient availability (Yan and Lu 2015). Similarly, long-term grazing had also increased Shannon-Wiener index and Pielou evenness index. This finding is similar to that of Xiong et al. (2014), who reported that Shannon-Wiener index and Pielou evenness index were significantly lower in the grazing excluded plots than in the adjacent grazing plots at all sites. For different grazing seasons, our studies revealed that winter grazing significantly increased species richness, ShannonWiener index and Pielou evenness index, perhaps because winter grazing could reduce the accumulation of grassland litter, and the sufficient sunshine might be the main factor contributing to the increase of plant diversity indices (Zou et al. 2016b). Yak and Tibetan sheep are the dominant livestock grazing on the Tibetan Plateau (Cheng et al. 2016). Our meta-analysis indicated that yak grazing had no significant impact on plant diversity indices, but mixed grazing had significantly increased species richness and Pielou evenness index. It was worth-noting that the effect of Tibetan sheep grazing on Shannon-Wiener index and Pielou evenness index was more pronounced than yak and mixed grazing. This was presumably because there were differences between Tibetan sheep and yak in size and habits, including feeding and trampling (Cai et al. 2014). The increase of species richness was most pronounced in the alpine meadow under grazing, which could be attributed to the different components of different alpine grassland types.

Response of grassland biomass to grazing

Livestock grazing directly and indirectly affected the normal growth and biomass of grassland. In our meta-analysis, the results consistently demonstrated that grazing significantly decreased AGB and BGB (Fig. 5). The finding was supported by many previous studies that showed alpine grassland biomass decreased by grazing (Sun et al. 2011; Xiong et al. 2014; Yao et al. 2019). Among the different grazing intensity, heavy gazing had the most significant reduction in AGB and BGB by $55.4 \%$ and $31.4 \%$, 
respectively. However, light and moderate grazing had no significant effect on BGB. These results were in line with recent meta-analysis on global and national scales (Hao and He 2019; Tang et al. 2019). Besides, Yan et al. (2013) who performed a meta-analysis in China indicated that light and moderate grazing did not have significant effects on grassland BGB of 0-30 cm. Compared with medium and long duration grazing, the short-duration grazing decreased AGB most significantly in alpine grassland, but there was no significant change in BGB. It seemed that short-term grazing had less effect on soil trampling, which resulted in no significant effect on BGB, but reduced the aboveground dominant forage biomass. For different grazing seasons, grazing significantly decreased AGB and BGB, but winter had no significant effect on BGB. Especially, summer grazing had the greatest impact on AGB and BGB, which might be due to the following reasons. Firstly, summer was the growing season of alpine grassland on the Tibetan Plateau. Secondly, grassland stopped growing in large numbers in winter, but the underground root did not stop growing. The effect of mixed grazing on AGB was greater than yak and Tibetan sheep, and yak grazing had the greatest impact on BGB. This phenomenon might be due to the different living habits of yak and Tibetan sheep (Cheng et al. 2016). For the three grassland types, grazing reduced grassland $\mathrm{AGB}$ and $\mathrm{BGB}$, which is consistent with previous studies (Chen et al. 2018; Yan and Lu 2015; Zhao et al. 2016).

Response of soil $\mathrm{C}, \mathrm{N}$ and related variables to grazing Soil $\mathrm{C}$ and $\mathrm{N}$ are materials that store energy and limit plant productivity in terrestrial biomass (Song et al. 2017). Overall, our meta-analysis indicated that grazing significantly reduced SOC, TN, and C: N ratio in alpine grasslands (Fig. 5), which were in accordance with several other studies (Li et al. 2018b; Lu et al. 2017; Sun et al. 2011). This effect might be attributed to the reduction of the quantity of resources returning to soil, especially litter and belowground biomass allocation. With enhanced grazing intensity, 
only light grazing has a no significantly impact on SOC, TN and C: N ratio. Dong et al. (2012) and Tang et al. (2019) indicated that TN and SOC exhibited a downward trend with increasing grazing intensity. These facts implied that the turnover of plant materials, and excreta disruption of soil hastened the loss of soil C and $\mathrm{N}$ under different grazing pressure (Dong et al. 2012; Wu et al. 2010). It should be noted that SOC, TN and $\mathrm{C}$ : $\mathrm{N}$ ratio changed more significantly with long-duration of grazing, whereas shortduration grazing had the least effect on them. As shown in a previous study, long-term grazing reduced the input of soil organic matter in grassland (Zhang et al. 2018). Likewise, Zhou et al. (2017a) also demonstrated a negative linear relationship of grazing duration with soil carbon and nitrogen in a global perspective. All grazing seasons had a significant reduction in SOC and TN, but winter and annual grazing did not change C: N ratio (Fig. 4). This was consistent with Wang et al. (2018), probably because livestock feeding reduced the ability of the aboveground organic matter to return to soil. Compared to Yak and Tibetan sheep grazing, mixed grazing had the greatest impact on SOC, TN and C: N ratio in alpine grassland, probably due to the trampling and feeding of Tibetan sheep and yak. In term of grassland types, grazing significantly decreased SOC, TN and C: $\mathrm{N}$ ratio in alpine meadow, but the results were opposite for alpine steppe and desert steppe, possibly because of the different soil temperature and SM and the limited number of investigations in a desert steppe.

The decrease of SM and the increase of soil BD in alpine grassland are the main manifestations of grazing on soil properties. Our synthesis indicated that grazing significantly increased soil BD and $\mathrm{pH}$, but significantly decreased soil moisture. This finding agrees with the recent meta-analysis of grassland in China (Hao and He 2019). In the case of alpine grasslands, Zheng et al. (2012) and Lu et al. (2015a) found that grazing had positive effects on soil $\mathrm{BD}$ and $\mathrm{pH}$. Grazing increased the soil $\mathrm{BD}$, which led to a decrease in soil moisture and an increase in soil pH. The meta-analysis of Byrnes et al. (2018) showed 
similar results. We speculate that the following reasons might explain these results. Firstly, it could probably be attributed to the trampling on the soil by grazing (Davidson et al. 2017). Secondly, it was likely because of the accumulation of excreta and urine from grazing livestock (Dong et al. 2012; Yang et al. 2016). Different grazing duration significantly increased soil BD and $\mathrm{pH}$, but reduced soil water. Meanwhile, long-duration grazing significantly increased soil $\mathrm{pH}$, probably because grazing had an additive effect on soil trampling. Regarding grazing season, summer grazing most significantly increased soil BD, but had little effects on SM, which is likely due to the abundant precipitation in summer. Furthermore, our results showed that BD was negatively correlated with MAP (Table 1). The effect of Tibetan sheep grazing on soil BD and $\mathrm{pH}$ was more than that of mixed grazing (Fig. 5), which was in agreement with a previous study (Xiao et al. 2018). Grazing significantly increased the soil BD and pH of alpine grassland, based on a number of studies in alpine steppe and desert steppe. Grazing significantly reduced soil $\mathrm{BD}$ in the alpine desert steppe, but did no change soil BD in the alpine steppe, possibly because different grassland types had different soil properties.

Regulating mechanisms of climate factors

The Tibet Plateau is the highest geographic in the world with the harshest and most sensitive environment, and climate change will affect grassland vegetation growth (Wu et al. 2014a). In this study, we found that each single plant diversity indices index was not significantly relevant to MAT and MAP under grazing. This result may indicate that grazing disturbance was the main cause of changes in grassland species diversity (Collins and Barber 1985). There was no evidence for variation of responses of plant biomass to grazing as a function of climate (Table 1), which might be attributed to the reduction of biomass induced by grazing. Suitable temperature and rainfall helped increase soil microbial activity and accelerate soil organic matter mineralization (Ghee et al. 2013). However, our results showed that 
SOC and TN were not significantly correlated with climate under grazing, probable because grazing decreased biomass and litter, resulting in less soil organic matter and nutrients. In addition, the response ratio of $\mathrm{C}$ : $\mathrm{N}$ ratio exhibited a negative correlation with MAT, indicating that MAT played an important role in C: $\mathrm{N}$ ratio regulation (Klaminder et al. 2009). Furthermore, our results showed that the response ratio of SM and soil $\mathrm{pH}$ had a significant negative correlation with MAT under grazing, largely resulting from increase in soil evaporation and soil temperature by grazing (Wolf et al. 2010).

Compared with the findings of grazing studies in other regions

Grazing is an important form of alpine grassland utilization on the Tibetan Plateau. Understanding the effects of grazing direction and extent on soil and plant diversity in alpine grassland, can help provide a reference for grassland management practices (Wang et al. 2017). From the perspective of protecting plant diversity, our results showed that grazing was beneficial to increase in species diversity of alpine grassland compared to non-grazing, especially under moderate grazing, long-duration, winter and mixed grazing. This finding was consistent with a recent global scale meta-analysis (Gao and Carmel 2020).

These changes may be because grazing reduces plant height, cover, dominance and litter, increase light availability (Ren et al. 2016; Segre et al. 2016). Moreover, Joubert et al. (2017) also found that moderate grazing sustains plant diversity in Afromontane grassland, consistent with the predictions of the intermediate disturbance hypothesis. Compared with the meta-analysis based on 140 studies over a China scale performed by Hao and He (2019), our meta-analysis indicated that the effects of grazing on the AGB of the Tibetan Plateau grassland was greater than in China scale, but the opposite results were shown for BGB. It is shown that grazing leads to more BGB allocation, which is conducive to the survival of high-altitude plants in an environment with low temperature and limited nutrients (Yan et al. 2020). From the perspective of soil carbon and nitrogen stock, except that light grazing had no significant effect 
on SOC, TN and soil C:N ratio, other grazing management significantly decreased SOC and TN, which indicated that light grazing was suitable for the sustainable development of alpine grasslands. These results were consistent with that at the China scale (Zhan et al. 2020) and global scale (Tang et al. 2019; Zhou et al. 2017b).

\section{Conclusions}

This study explored the effects of grazing on plant diversity, biomass and soil properties in alpine grasslands on the Tibetan Plateau. Our results revealed that moderate grazing showed the most significant increase species richness, Shannon-Wiener index and Pielou evenness index, indicating that moderate grazing intensity might be an effective management approach for improving the species diversity of alpine grassland on the Tibetan Plateau. With increasing grazing intensity, there was a greater decrease in the loss of biomass, SOC and TN. In addition, long duration ( $>5$ years), winter and mixed grazing can enhance grassland diversity. Given these results, this study indicates that grazing should be chosen according to local environmental conditions, in order to realize the sustainable utilization, biodiversity and environment protection of alpine grassland on the Tibetan Plateau.

\section{Acknowledgments}

We are thankful to all the scientists whose research work was used to perform this meta-analysis. This work was partly supported by the National Key Research and Development Program of China (2018YFC0406602, 2016YFC0501901), the NSFC grants (41471450, 31170430), Key Specitial Founation/Project of Science and Technology Department of Qinghai Province (2019-SF-A12), the Second Tibetan Plateau Scientific Expedition and Research Program (2019QZKK0302), the 111 Project (B12002) and the Fundamental Research Fund for the Central Universities (lzujbky-2019-it03). 
392

393

394

395

396

397

398

399

400

401

402

403

404

405

406

407

408

409

410

411

412

413

\section{References}

Byrnes RC, Eastburn DJ, Tate KW, Roche LM (2018) A Global Meta-Analysis of Grazing Impacts on Soil Health Indicators. J Environ Qual 47: 758-765. doi: 10.2134/jeq2017.08.0313.

Cai YJ, Wang XD, Tian LL, Zhao H, Lu XY, Yan Y (2014) The impact of excretal returns from yak and Tibetan sheep dung on nitrous oxide emissions in an alpine steppe on the Qinghai-Tibetan Plateau. Soil Biol Biochem 76: 90-99. doi: 10.1016/j.soilbio.2014.05.008.

Cao J, Holden NM, Lu XT, Du G (2011) The effect of grazing management on plant species richness on the Qinghai-Tibetan Plateau. Grass Forage Sci 66: 333-336. doi: 10.1111/j.13652494.2011.00793.x.

Chen J, Luo YQ, Xia JY, Zhou XH, Niu SL, Shelton S, Guo W, Liu SX, Dai WT, Cao JJ (2018) Divergent responses of ecosystem respiration components to livestock exclusion on the Qinghai Tibetan Plateau. Land Degrad Dev 29: 1726-1737. doi: 10.1002/ldr.2981.

Cheng Y, Cai YJ, Wang SQ (2016) Yak and Tibetan sheep dung return enhance soil N supply and retention in two alpine grasslands in the Qinghai-Tibetan Plateau. Biol Fertil Soils 52: 413-422. doi: 10.1007/s00374-016-1088-6.

Collins SL, Barber SC (1985) EFFECTS OF DISTURBANCE ON DIVERSITY IN MIXED-GRASS PRAIRIE. Vegetatio 64: 87-94.

Davidson KE, Fowler MS, Skov MW, Doerr SH, Beaumont N, Griffin JN (2017) Livestock grazing alters multiple ecosystem properties and services in salt marshes: a meta-analysis. Journal of Applied Ecology 54: 1395-1405. doi: 10.1111/1365-2664.12892.

Dlamini P, Chivenge P, Chaplot V (2016) Overgrazing decreases soil organic carbon stocks the most under dry climates and low soil pH: A meta-analysis shows. Agric Ecosyst Environ 221: 258-269. 
doi: 10.1016/j.agee.2016.01.026.

Dong QM, Zhao XQ, Wu GL, Shi JJ, Wang YL, Sheng L (2012) Response of soil properties to yak grazing intensity in a Kobresia parva-meadow on the Qinghai-Tibetan Plateau, China. Journal of Soil Science and Plant Nutrition 12: 535-546. doi: 10.4067/s0718-95162012005000024.

Ganjurjav H, Duan M-j, Wan Y-f, Zhang W-n, Gao Q-z, Li Y, Jiangcun W-z, Danjiu L-b, Guo H-b (2015) Effects of grazing by large herbivores on plant diversity and productivity of semi-arid alpine steppe on the Qinghai-Tibetan Plateau. The Rangeland Journal 37: 389-397. doi: $10.1071 /$ rj14127.

Gao J, Carmel Y (2020) A global meta-analysis of grazing effects on plant richness. Agriculture, Ecosystems \& Environment 302. doi: 10.1016/j.agee.2020.107072.

Ghee C, Neilson R, Hallett PD, Robinson D, Paterson E (2013) Priming of soil organic matter mineralisation is intrinsically insensitive to temperature. Soil Biol Biochem 66: 20-28. doi: 10.1016/j.soilbio.2013.06.020.

Gurevitch J, Koricheva J, Nakagawa S, Stewart G (2018) Meta-analysis and the science of research synthesis. Nature 555: 175-182. doi: 10.1038/nature25753.

Hao YQ, He ZW (2019) Effects of grazing patterns on grassland biomass and soil environments in China: A meta-analysis. Plos One 14: 15. doi: 10.1371/journal.pone.0215223.

He M, Zhou GY, Yuan TF, van Groenigen KJ, Shao JJ, Zhou XH (2020) Grazing intensity significantly changes the C : N : P stoichiometry in grassland ecosystems. Glob Ecol Biogeogr 29: 355-369. doi: $10.1111 /$ geb. 13028 .

Hedges LV, Gurevitch J, Curtis PS (1999) The meta-analysis of response ratios in experimental ecology. Ecology 80: 1150-1156. doi: 10.2307/177062. 
Herrero-Jauregui C, Oesterheld M (2018) Effects of grazing intensity on plant richness and diversity: a meta-analysis. Oikos 127: 757-766. doi: 10.1111/oik.04893.

Janssens IA, Dieleman W, Luyssaert S, Subke JA, Reichstein M, Ceulemans R, Ciais P, Dolman AJ, Grace J, Matteucci G, Papale D, Piao SL, Schulze ED, Tang J, Law BE (2010) Reduction of forest soil respiration in response to nitrogen deposition. Nat Geosci 3: 315-322. doi: 10.1038/ngeo844.

Joubert L, Pryke JS, Samways MJ (2017) Moderate grazing sustains plant diversity in Afromontane grassland. Appl Veg Sci 20: 340-351. doi: 10.1111/avsc.12310.

Klaminder J, Yoo K, Giesler R (2009) Soil carbon accumulation in the dry tundra: Important role played by precipitation. J Geophys Res-Biogeosci 114: 9. doi: 10.1029/2009jg000947.

Li C, Wulf H, Schmid B, He J-S, Schaepman ME (2018a) Estimating Plant Traits of Alpine Grasslands on the Qinghai-Tibetan Plateau Using Remote Sensing. IEEE Journal of Selected Topics in Applied Earth Observations and Remote Sensing 11: 2263-2275. doi: 10.1109/jstars.2018.2824901.

Li G, Zhang Z, Shi LL, Zhou Y, Yang M, Cao JX, Wu SH, Lei GC (2018b) Effects of Different Grazing Intensities on Soil C, N, and P in an Alpine Meadow on the QinghaiTibetan Plateau, China. Int J Environ Res Public Health 15: 16. doi: 10.3390/ijerph15112584.

Li HQ, Zhang FW, Mao SJ, Zhu JB, Yang YS, He HD, Li YN (2016a) Effects of Grazing Exclusion on Soil Properties in Maqin Alpine Meadow, Tibetan Plateau, China. Pol J Environ Stud 25: 15831587. doi: 10.15244/pjoes/62099.

Li W, Cao WX, Wang JL, Li XL, Xu CL, Shi SL (2017) Effects of grazing regime on vegetation structure, productivity, soil quality, carbon and nitrogen storage of alpine meadow on the QinghaiTibetan Plateau. Ecological Engineering 98: 123-133. doi: 10.1016/j.ecoleng.2016.10.026. 
Li W, Huang HZ, Zhang ZN, Wu GL (2011) Effects of grazing on the soil properties and C and N storage in relation to biomass allocation in an alpine meadow. Journal of Soil Science and Plant Nutrition 11: 27-39. doi: 10.4067/S0718-95162011000400003.

Li W, Tian F-P, Ren Z-W, Huang H-Z, Zhang Z-N (2013) Effects of grazing and fertilization on the relationship between species abundance and functional traits in an alpine meadow community on the Tibetan Plateau. Nordic Journal of Botany 31: 247-255. doi: 10.1111/j.17561051.2012.01511.x.

Li Y, Niu SL, Yu GR (2016b) Aggravated phosphorus limitation on biomass production under increasing nitrogen loading: a meta-analysis. Glob Change Biol 22: 934-943. doi: $10.1111 /$ gcb. 13125 .

Lin XW, Zhang ZH, Wang SP, Hu YG, Xu GP, Luo CY, Chang XF, Duan JC, Lin QY, Xu B, Wang YF, Zhao XQ, Xie ZB (2011) Response of ecosystem respiration to warming and grazing during the growing seasons in the alpine meadow on the Tibetan plateau. Agric For Meteorol 151: 792-802. doi: 10.1016/j.agrformet.2011.01.009.

Liu C, Li W, Xu J, Wei W, Xue P, Yan H (2021) Response of soil nutrients and stoichiometry to grazing management in alpine grassland on the Qinghai-Tibet Plateau. Soil Tillage Res 206. doi: 10.1016/j.still.2020.104822.

Lu X, Yan Y, Sun J, Zhang X, Chen Y, Wang X, Cheng G (2015a) Short-term grazing exclusion has no impact on soil properties and nutrients of degraded alpine grassland in Tibet, China. Solid Earth 6: 1195-1205. doi: 10.5194/se-6-1195-2015.

Lu XY, Kelsey KC, Yan Y, Sun J, Wang XD, Cheng GW, Neff JC (2017) Effects of grazing on ecosystem structure and function of alpine grasslands in Qinghai-Tibetan Plateau: a synthesis. 
481

Lu XY, Yan Y, Sun J, Zhang XK, Chen YC, Wang XD, Cheng GW (2015b) Carbon, nitrogen, and phosphorus storage in alpine grassland ecosystems of Tibet: effects of grazing exclusion. Ecol Evol 5: 4492-4504. doi: 10.1002/ece3.1732.

Luo YQ, Hui DF, Zhang DQ (2006) Elevated CO2 stimulates net accumulations of carbon and nitrogen in land ecosystems: A meta-analysis. Ecology 87: 53-63. doi: 10.1890/04-1724.

Niu KC, Choler P, Zhao BB, Du GZ (2009) The allometry of reproductive biomass in response to land use in Tibetan alpine grasslands. Funct Ecol 23: 274-283. doi: 10.1111/j.1365-2435.2008.01502.x.

Ren CJ, Chen J, Lu XJ, Doughty R, Zhao FZ, Zhong ZK, Han XH, Yang GH, Feng YZ, Ren GX (2018) Responses of soil total microbial biomass and community compositions to rainfall reductions. Soil Biol Biochem 116: 4-10. doi: 10.1016/j.soilbio.2017.09.028.

Ren Y, Lü Y, Fu B (2016) Quantifying the impacts of grassland restoration on biodiversity and ecosystem services in China: A meta-analysis. Ecological Engineering 95: 542-550. doi: 10.1016/j.ecoleng.2016.06.082.

Rosenberg MS (2005) The file-drawer problem revisited: A general weighted method for calculating fail-safe numbers in meta-analysis. Evolution 59: 464-468. doi: 10.1111/j.00143820.2005.tb01004.x.

Rosenberg MS, Adams DC, Gurevitch J (2000) MetaWin: statistical software for meta-analysis. Sinauer Associates, Sunderland, MA.

Scurlock JMO, Hall DO (1998) The global carbon sink: a grassland perspective. Glob Change Biol 4: 229-233. doi: 10.1046/j.1365-2486.1998.00151.x.

Segre H, DeMalach N, Henkin Z, Kadmon R (2016) Quantifying Competitive Exclusion and 
Competitive Release in Ecological Communities: A Conceptual Framework and a Case Study. Plos One 11: 14. doi: 10.1371/journal.pone.0160798.

Shi XM, Li XG, Li CT, Zhao Y, Shang ZH, Ma QF (2013) Grazing exclusion decreases soil organic C storage at an alpine grassland of the Qinghai-Tibetan Plateau. Ecological Engineering 57: 183187. doi: 10.1016/j.ecoleng.2013.04.032.

Song Y, Zou YC, Wang GP, Yu XF (2017) Altered soil carbon and nitrogen cycles due to the freezethaw effect: A meta-analysis. Soil Biol Biochem 109: 35-49. doi: 10.1016/j.soilbio.2017.01.020.

Sun DS, Wesche K, Chen DD, Zhang SH, Wu GL, Du GZ, Comerford NB (2011) Grazing depresses soil carbon storage through changing plant biomass and composition in a Tibetan alpine meadow. Plant Soil Environ 57: 271-278. doi: 10.17221/7/2011-Pse.

Sun G, Zhu-Barker X, Chen DM, Liu L, Zhang NN, Shi CG, He LP, Lei YB (2017) Responses of root exudation and nutrient cycling to grazing intensities and recovery practices in an alpine meadow: An implication for pasture management. Plant Soil 416: 515-525. doi: 10.1007/s11104-017-32367.

Sun Y, He XZ, Hou FJ, Wang ZF, Chang SH (2018) Grazing increases litter decomposition rate but decreases nitrogen release rate in an alpine meadow. Biogeosciences 15: 4233-4243. doi: 10.5194/bg-15-4233-2018.

Tang SM, Wang K, Xiang YZ, Tian DS, Wang JS, Liu YS, Cao B, Guo D, Niu SL (2019) Heavy grazing reduces grassland soil greenhouse gas fluxes: A global meta-analysis. Sci Total Environ 654: 1218-1224. doi: 10.1016/j.scitotenv.2018.11.082.

Tian L, Zhang YJ, Zhu JT (2014) Decreased surface albedo driven by denser vegetation on the Tibetan Plateau. Environ Res Lett 9: 11. doi: 10.1088/1748-9326/9/10/104001. 
524

525

526

527

528

529

530

531

532

533

534

535

536

537

538

539

540

541

542

Wang H, Li J, Zhang Q, Liu J, Yi B, Li Y, Wang J, Di H (2019) Grazing and enclosure alter the vertical distribution of organic nitrogen pools and bacterial communities in semiarid grassland soils. Plant Soil. doi: 10.1007/s11104-019-04045-6.

Wang TW, Zhang Z, Li ZB, Li P (2017) Grazing management affects plant diversity and soil properties in a temperate steppe in northern China. Catena 158: 141-147. doi: 10.1016/j.catena.2017.06.020.

Wang YX, Hodgkinson KC, Hou FJ, Wang ZF, Chang SH (2018) An evaluation of governmentrecommended stocking systems for sustaining pastoral businesses and ecosystems of the Alpine Meadows of the Qinghai-Tibetan Plateau. Ecol Evol 8: 4252-4264. doi: 10.1002/ece3.3960.

Wolf B, Zheng XH, Brueggemann N, Chen WW, Dannenmann M, Han XG, Sutton MA, Wu HH, Yao ZS, Butterbach-Bahl K (2010) Grazing-induced reduction of natural nitrous oxide release from continental steppe. Nature 464: 881-884. doi: 10.1038/nature08931.

Wu GL, Liu ZH, Zhang L, Chen JM, Hu TM (2010) Long-term fencing improved soil properties and soil organic carbon storage in an alpine swamp meadow of western China. Plant Soil 332: 331337. doi: 10.1007/s11104-010-0299-0.

Wu J, Zhang X, Shen Z, Shi P, Yu C, Chen B (2014a) Effects of livestock exclusion and climate change on aboveground biomass accumulation in alpine pastures across the Northern Tibetan Plateau. Chinese Science Bulletin 59: 4332-4340. doi: 10.1007/s11434-014-0362-y.

Wu JS, Shen ZX, Shi PL, Zhou YT, Zhang XZ (2014b) Effects of Grazing Exclusion on Plant Functional Group Diversity Alpine Grasslands along a Precipitation Gradient on the Northern Tibetan Plateau. Arct Antarct Alp Res 46: 419-429. doi: 10.1657/1938-4246-46.2.419.

Xiao H, Peng Z, Xu CL, Zhang DG, Chai JL, Pan TT, Yu XJ (2018) Yak and Tibetan sheep trampling inhibit reproductive and photosynthetic traits of Medicago ruthenica var. inschanica. Environ 
Xiong D, Shi P, Zhang X, Zou CB (2016) Effects of grazing exclusion on carbon sequestration and plant diversity in grasslands of China-A meta-analysis. Ecological Engineering 94: 647-655. doi: 10.1016/j.ecoleng.2016.06.124.

Xiong DP, Shi PL, Sun YL, Wu JS, Zhang XZ (2014) Effects of grazing exclusion on plant productivity

Yan L, Li Y, Wang L, Zhang XD, Wang JZ, Wu HD, Yan ZQ, Zhang KR, Kang XM (2020) Grazing significantly increases root shoot ratio but decreases soil organic carbon in Qinghai-Tibetan Plateau grasslands: A hierarchical meta-analysis. Land Degrad Dev: 10. doi: 10.1002/ldr.3606.

Yan L, Zhou G, Zhang F (2013) Effects of different grazing intensities on grassland production in China: a meta-analysis. PLoS One 8: e81466. doi: 10.1371/journal.pone.0081466.

Yan Y, Lu XY (2015) Is grazing exclusion effective in restoring vegetation in degraded alpine grasslands in Tibet, China? PeerJ 3: 16. doi: 10.7717/peerj.1020.

Yang Z, Xiong W, Xu Y, Jiang L, Zhu E, Zhan W, He Y, Zhu D, Zhu Q, Peng C, Chen H (2016) Soil properties and species composition under different grazing intensity in an alpine meadow on the eastern Tibetan Plateau, China. Environ Monit Assess 188: 678. doi: 10.1007/s10661-016-5663-y.

Yao XX, Wu JP, Gong XY, Lang X, Wang CL, Song SZ, Ahmad AA (2019) Effects of long term fencing on biomass, coverage, density, biodiversity and nutritional values of vegetation community in an alpine meadow of the Qinghai-Tibet Plateau. Ecological Engineering 130: 80-93. doi: 10.1016/j.ecoleng.2019.01.016.

Yu L, Chen Y, Sun W, Huang Y (2019) Effects of grazing exclusion on soil carbon dynamics in alpine 

Meta-analysis demonstrating that moderate grazing can improve the soil quality across China's grassland ecosystems. Appl Soil Ecol 147: 6. doi: 10.1016/j.apsoil.2019.103438. response to long-term cattle grazing on sloped rough fescue grassland in the foothills of the Rocky Mountains, Alberta. Geoderma 318: 9-15. doi: 10.1016/j.geoderma.2017.12.019. 
analysis. Glob Chang Biol 23: 1167-1179. doi: 10.1111/gcb.13431.

Zhou G, Zhou X, Nie Y, Bai SH, Zhou L, Shao J, Cheng W, Wang J, Hu F, Fu Y (2018) Droughtinduced changes in root biomass largely result from altered root morphological traits: Evidence from a synthesis of global field trials. Plant Cell Environ 41: 2589-2599. doi: 10.1111/pce.13356.

Zhou GY, Zhou XH, He YH, Shao JJ, Hu ZH, Liu RQ, Zhou HM, Hosseinibai S (2017b) Grazing intensity significantly affects belowground carbon and nitrogen cycling in grassland ecosystems: a meta-analysis. Glob Change Biol 23: 1167-1179. doi: 10.1111/gcb.13431.

Zhou HK, Tang YH, Zhao XQ, Zhou L (2006) Long-term grazing alters species composition and biomass of a shrub meadow on the Qinghai-Tibet Plateau. Pak J Bot 38: 1055-1069.

Zou J, Luo C, Xu X, Zhao N, Zhao L, Zhao X (2016a) Relationship of plant diversity with litter and soil available nitrogen in an alpine meadow under a 9-year grazing exclusion. Ecological Research 31: 841-851. doi: 10.1007/s11284-016-1394-3.

Zou JR, Luo CY, Xu XL, Zhao N, Zhao L, Zhao XQ (2016b) Relationship of plant diversity with litter and soil available nitrogen in an alpine meadow under a 9-year grazing exclusion. Ecological Research 31: 841-851. doi: 10.1007/s11284-016-1394-3. 


\section{Figures}

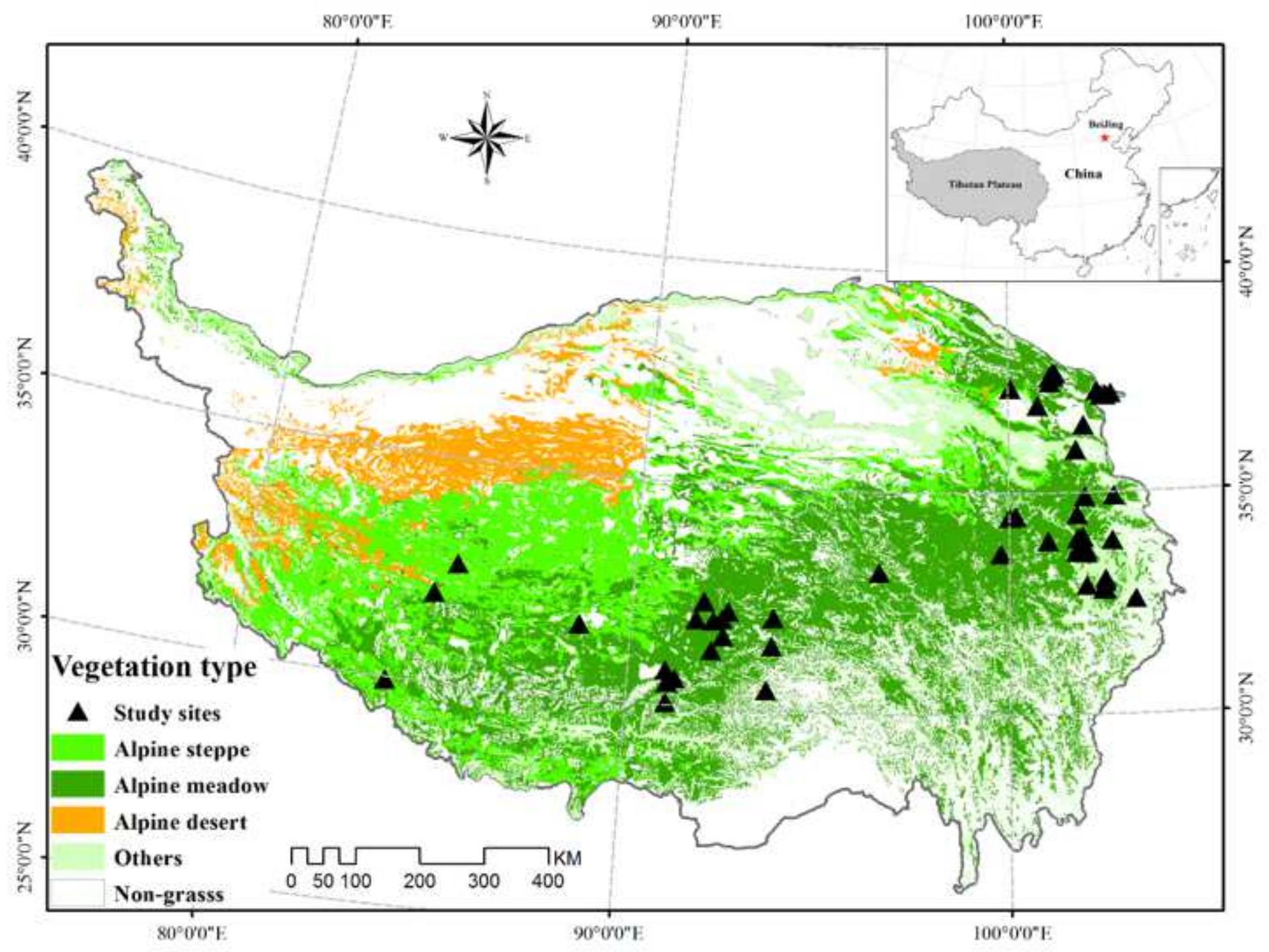

Figure 1

The distribution of grazing experiments selected in this meta-analysis on the Tibet Plateau. The geographical location of field studies was mapped in ArcGIS 10.2 (https://www.esri.com/). Note: The designations employed and the presentation of the material on this map do not imply the expression of any opinion whatsoever on the part of Research Square concerning the legal status of any country, territory, city or area or of its authorities, or concerning the delimitation of its frontiers or boundaries. This map has been provided by the authors. 

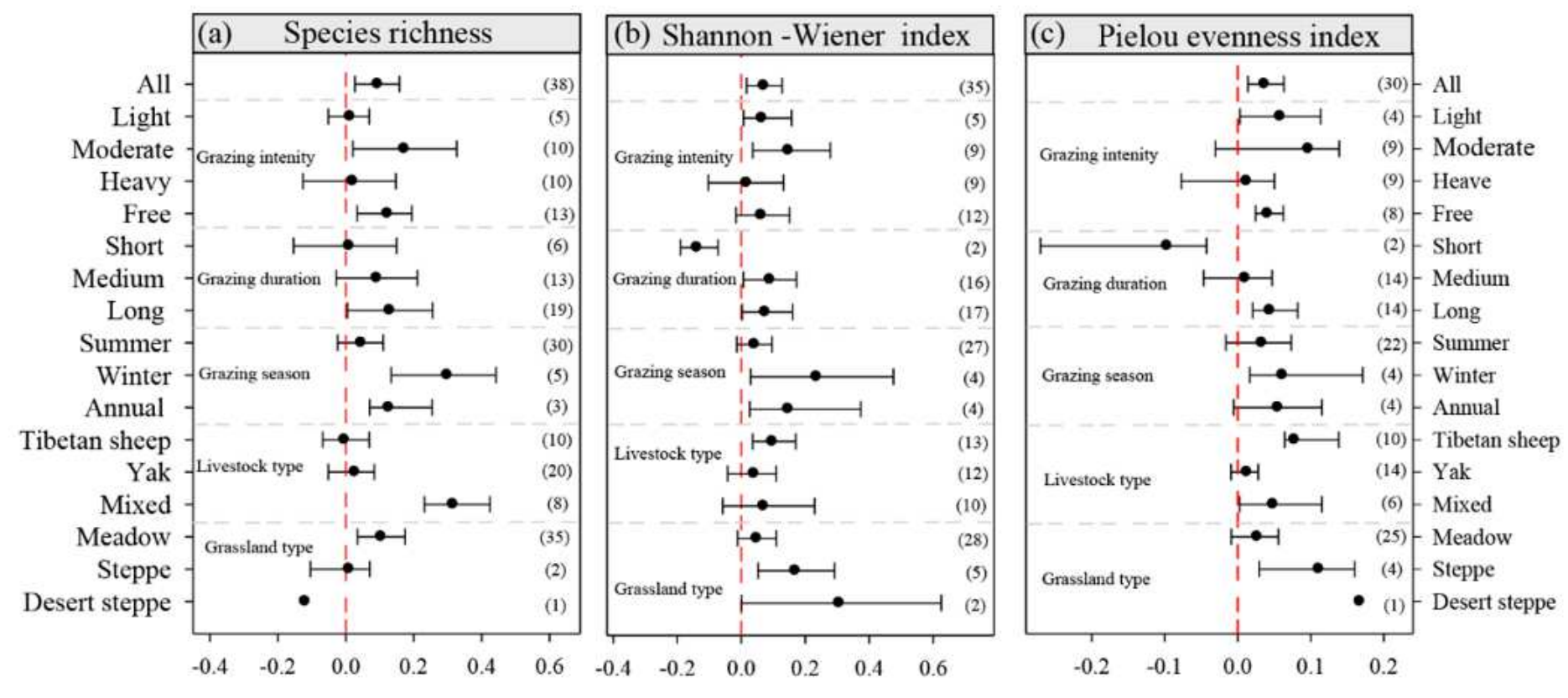

Weighted response ration $\left(R R_{++}\right)$

\section{Figure 2}

Weighted response ratio (RR++) of (a) species richness, (b) Shannon-Wiener index, and (c) Pielou evenness index in response to grazing. The variables are categorized into different groups by grazing intensity, grazing duration, grazing season, livestock type, and grassland type. The error bars represent bootstrap $95 \%$ confidence intervals (Cls). If $95 \%$ Cls do not overlap with zero, the grazing effect is considered significant. Data on the right side of each panel represents the sample sizes of observations.
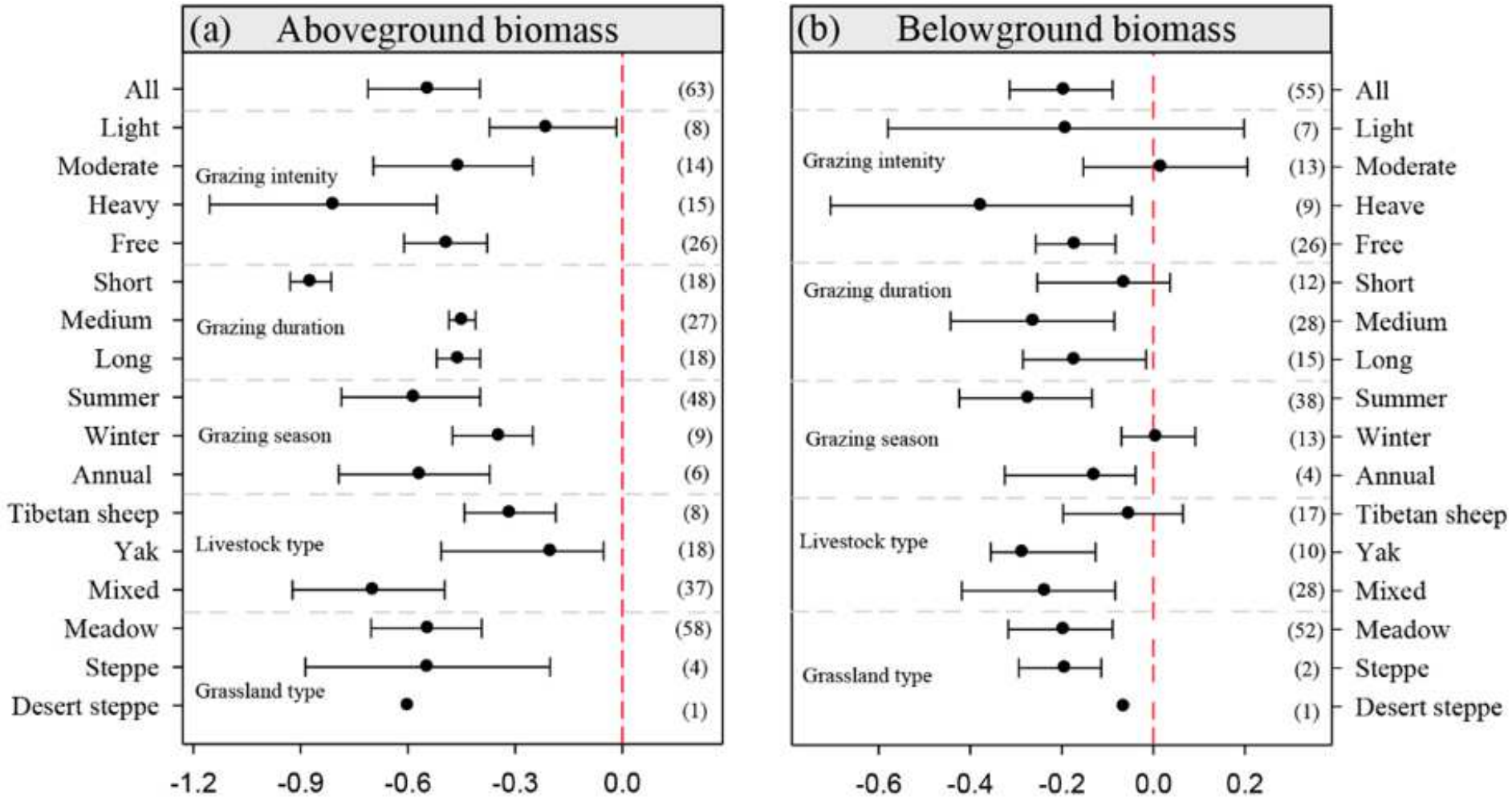

Weighted response ration $\left(\mathrm{RR}_{++}\right)$ 


\section{Figure 3}

Weighted response ratio (RR++) of (a) aboveground biomass and (b) belowground biomass in response to grazing. The variables are categorized into different groups by grazing intensity, grazing duration, grazing season, livestock type, and grassland type. The error bars represent bootstrap $95 \%$ confidence intervals (Cls). If $95 \%$ Cls do not overlap with zero, the grazing effect is considered significant. Data on the right side of each panel represent the sample sizes of observations.
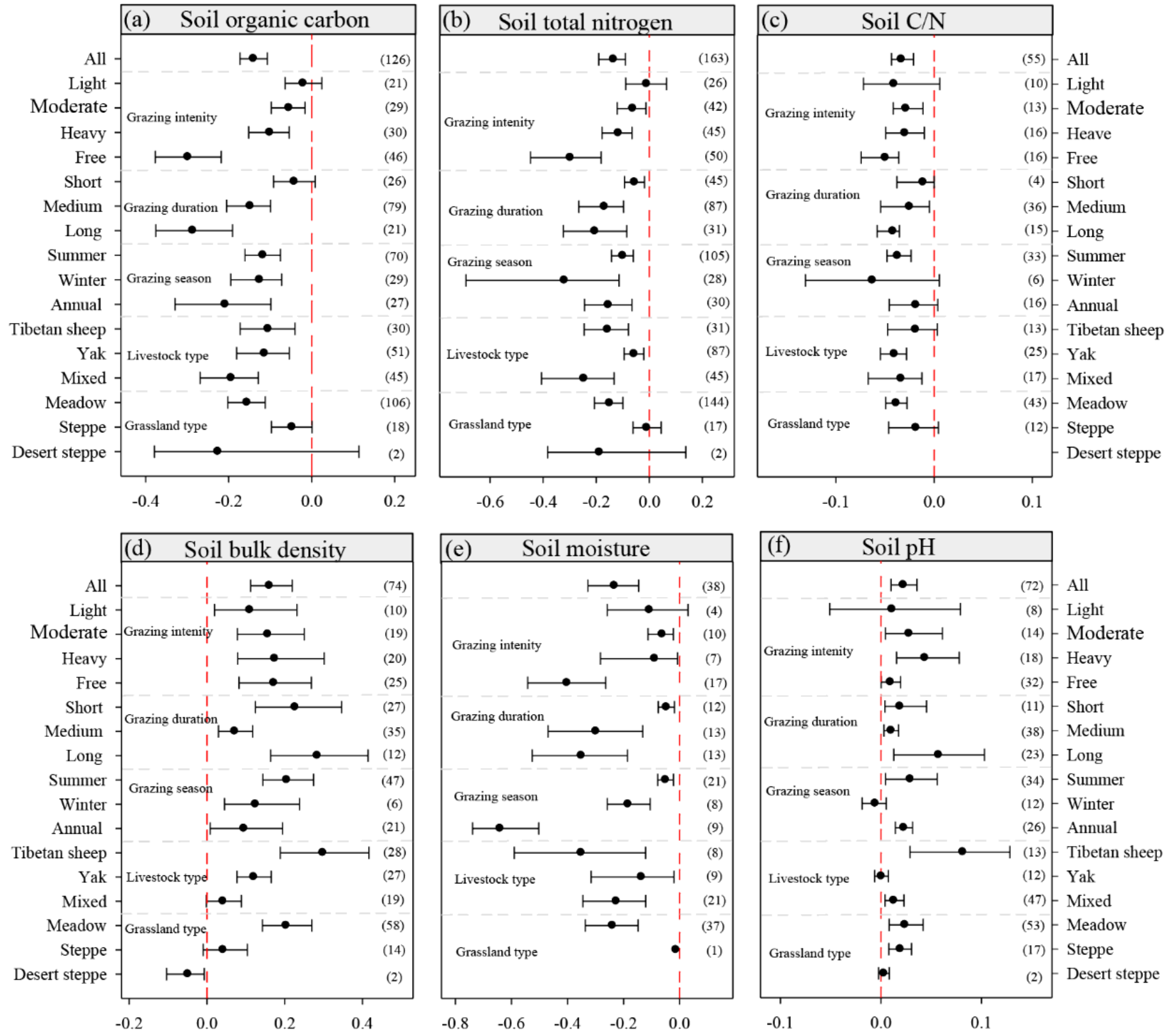

Weighted response ration $\left(\mathrm{RR}_{++}\right)$

\section{Figure 4}

Weighted response ratio (RR++) of soil organic carbon (SOC, a), soil total nitrogen (TN, b), soil C: $\mathrm{N}$ ratio $(\mathrm{c})$, soil bulk density $(\mathrm{BD}, \mathrm{d})$, soil moisture $(\mathrm{SM}, \mathrm{e})$ and soil $\mathrm{pH}(\mathrm{f})$ in response to grazing. The variables are 
categorized into different groups by grazing intensity, grazing duration, grazing season, livestock type, and grassland type. The error bars represent bootstrap 95\% confidence intervals (Cls). If $95 \% \mathrm{Cls}$ do not overlap with zero, the grazing effect is considered significant. Data on the right side of each panel represent the sample sizes of observations.

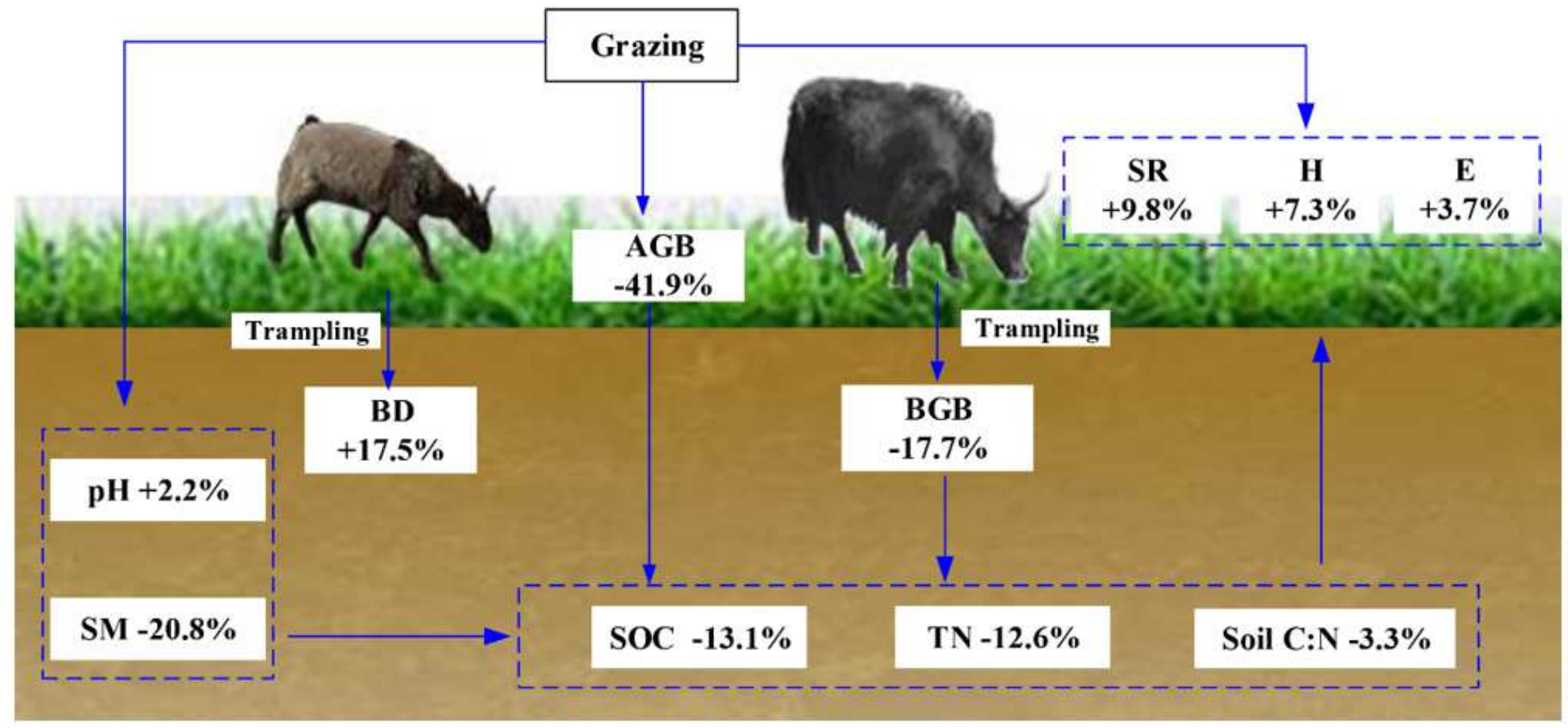

\section{Figure 5}

The conceptual figure summarizing the overall effects of grazing on plant diversity, biomass and soil C, N in alpine grassland and their possible mechanisms, this figure is based on our previous study (Liu et al., $2021)$. Data represent the percentage change $\left(e^{\wedge}\left(\square R R \mathbb{Z}_{-}(++)\right)-1\right) \times 100 \%$ of response variables caused by grazing treatment. SR, species richness; $\mathrm{H}$, Shannon-Wiener index; $E$, Pielou evenness index; AGB, aboveground biomass; BGB, belowground biomass; SOC, soil organic carbon; TN, soil total nitrogen; SCN, soil C: $\mathrm{N}$ ratio, $\mathrm{BD}$, soil bulk density; $\mathrm{SM}$, soil moisture.

\section{Supplementary Files}

This is a list of supplementary files associated with this preprint. Click to download.

- Supplementarymaterial.docx 